\title{
Effects of Soy- Containing Infant Formulas on Thyroid Gland
}

\author{
Ebrar Akkaya ${ }^{1}$, Serdar Culcu ${ }^{2}$, Erhan Aysan ${ }^{3}$, Mirkhalig Javadov ${ }^{3}$, and Alev Cumbul ${ }^{3}$ \\ ${ }^{1}$ Bezmialem Vakif University Faculty of Medicine \\ ${ }^{2}$ Ankara Dr Abdurrahman Yurtaslan Ankara Oncology Training and Research Hospital \\ ${ }^{3}$ Yeditepe University School of Medicine
}

October 1, 2020

\begin{abstract}
Background: Effects of soy-containing infant formulas on the thyroid gland is not clear We aimed to evaluate the effects of infant formulas with different quantities of soy content on the functional and histopathological characteristics of the thyroid gland. Method: Twenty-eight female Sprague-Dawley rats were divided into four groups. Group 1 was fed with standard pellet rat food (8g/day); Group 2 soy-free infant formula (8g/day); Group 3 low-dose (1.12g/100ml) soy-containing formula ( $8 \mathrm{~g} /$ day), and Group 4 high-dose $(2.64 \mathrm{~g} / 100 \mathrm{ml})$ soy-containing formula $(8 \mathrm{~g} /$ day $)$. Blood samples were collected from the subjects on day $0,30,60$, and 90 to evaluate thyroid functions. All subjects were sacrificed on day 90 . Thyroid glands were excised and examined histopathologically. Results: Serum levels of free T3, free T4, TSH, anti TPO, and anti TG were significantly higher in Group 4 compared to other groups $(\mathrm{p}<0.001, \mathrm{p}<0.01, \mathrm{p}<0.001, \mathrm{p}=0.002)$. No differences were found in the histopathological findings between the groups. Conclusion: Infant formulas with high soy content induce hyperthyroidism with high TSH levels. High levels of anti TPO and anti TG suggest that observed changes might have occurred via inflammatory mechanism.
\end{abstract}

\section{What's Known}

Soy based baby foods are on the markets daily. But as we in this study these are harmful for babies

\section{What's New}

Harmfulness of soy based baby foods for babies

\section{Introduction}

The soy plant and its products have an important place in the nutrition profiles of many countries, especially of Asian countries. The preventive effects of soy have been demonstrated against heart diseases [1-2] breast cancer, prostate cancer [3-4] and osteoporosis[5]. Despite those benefits, soy acts on the thyroid gland unfavourably. Several studies are available in the literature, reporting cases with hypothyroidism, goitre, and increased iodine need in association with the consumption of soybean.

Isoflavones constitute the most commonly studied component of soy. Soybean and most of its highly consumed products in Western populations contain isoflavones in glycosidic forms as genistin, daidzin, and glycitin. After oral intake, isoflavone glycosides are hydrolyzed by the intestinal microflora and converted into bioactive aglycone forms [6]. The aglycones genistein and daidzein irreversibly inactivate thyroid peroxidase; which is the enzyme binding iodine to the thyroglobulin molecule [7]. As is known, the production of T3 and T4 hormones requires iodine to be incorporated into the thyroglobulin molecule in the thyroid tissue [8-10]. These activities of genistein and daidzein increase the iodine demand in the organism and induce hypothyroidism [7]. In vitro studies demonstrate that genistein and daidzein show their effects even at very low concentrations [11]. 
Despite their known unfavourable effects on thyroid functions, it is noteworthy that soy and its products are still used extensively in infant formulas. Although studies about this subject matter are available in the literature, no studies have compared different doses of soy or investigated the histopathological effects of soy on the thyroid gland. We evaluated the effects of infant formulas with different quantities of soy content on the functional and histopathological characteristics of the thyroid gland.

\section{Methods}

The study protocol was approved by the local Animals Ethics Committee. Twenty-eight female SpragueDawley rats (one-month-old, mean weight $55 \mathrm{~g}$, weight range: $3-85 \mathrm{~g}$ ) were divided into four equal groups to carry out statistical analyses in a $95 \%$ confidence interval and at a sample power of 0.9 . The subjects were kept at standart fabricated cages of $40 \times 25 \times 25 \mathrm{~cm}$ in size with a stainless steel roof, plastic walls, and a plastic floor covered with wood shavings. The cages were exposed to 12 hours light and 12 hours dark cycles in a day. All procedures were carried out in compliance with the guidelines for the care and use of laboratory animals in the Declaration of Helsinki. The groups in the experiment and the diets given to the subjects in each groups are listed below:

Group $1(\mathrm{n}=7)$ : Standard pellet rat food $(8 \mathrm{~g} /$ day $)$

Group $2(\mathrm{n}=7)$ : Soy-free formula $(8 \mathrm{~g} /$ day, Hipp $\AA)$

Group-3 ( $\mathrm{n}=7)$ : Low-dose $(1.12 \mathrm{~g} / 100 \mathrm{ml})$ soy-containing formula $(8 \mathrm{~g} /$ day, Similac $\AA)$

Group $4(\mathrm{n}=7)$ : High-dose $(2.64 \mathrm{~g} / 100 \mathrm{ml})$ soy-containing formula (8g/day, Modilac@).

Before starting the feeding regimens, blood samples were collected from the tail veins of the rats on day 0 and days 30,60, and 90 to evaluate the levels of free T3, free T4, thyroid stimulating hormone (TSH), antithyroglobulin antibody (Anti TG), and anti-troponin antibody (Anti TPO). All subjects were weighed weekly and the measured body weights were recorded. All subjects were sacrificed by cervical dislocation on the 90th day of the experiment. After making an anterior longitudinal incision in the necks of the rats; their thyroid glands were totally excised, placed in containers containing formaldehyde, and submitted to the pathology laboratory for the histopathological examination. The tissue sections obtained from the thyroid glands of the rats were stained with hematoxylin and eosin. A pathologist blinded to the experimental groups examined the specimens and scored the histopathological findings according to the histopathological fibrosis scoring system (Table 1).

\section{Statistical Analysis}

SPSS version 11.5 statistical program was used in the analysis of the data. For descriptive analyses; the quantitative variables were summarized as mean \pm standard deviation and median (minimum-maximum), while the qualitative variables were summarized in percentiles. In order to test whether categorical differences were present in the quantitative variables with more than two categories; the one-way ANOVA test was used when the normal distribution presumptions were met, whereas the Kruskal-Wallis H test was used when the normal distribution assumptions were not met. Differences between two dependent quantitative variables were analyzed with the paired t-test when normal distribution assumptions were provided or with the Wilcoxon signed-rank test when normal distribution assumptions were not provided. The statistical significance level was accepted as 0.05 .

\section{Results}

No statistically significant differences were found in the levels of TSH, free T3, and free T4 in the groups 1, 2, and 3. Changes in the TSH, free T3, and free T4 levels occurred at the highest significance level in Group 4. The changes were the least in the levels of TSH in Group 2, in the levels of free T3 in Group 1, and in the levels of free T4 in Group 3 (table 2).

Statistically significant differences in the levels of Anti TPO and Anti TG occurred only in Group 4 (table $2, \mathrm{p}<0.01$, and $\mathrm{p}=0.02$ respectively). 
The histopathological fibrosis scores found in the tissue specimens of the subjects are shown in table 3 . There were no statistically significant differences in the histopathological fibrosis scores between the groups $(\mathrm{p}=0.714)$. The mean body weights of all subjects in the experiment on days 0 and 90 were $55.38 \mathrm{~g}$ and $331.30 \mathrm{~g}$, respectively. The changes in the body weight of the subjects by the groups are shown in table 4 . The changes in the body weights of the subjects were not statistically different with a standard deviation value of $4.92(\mathrm{p}=0.068)$.

\section{Discussion}

The studies about the effects of soy on the thyroid gland became available in the literature quite a long time ago [12-13]. The hormonal and non-hormonal effects of soy have been demonstrated to occur primarily via isoflavones [14-15]. Isoflavones constitute a subclass of a larger and more ubiquitous group of plant chemicals, the flavonoids. The three isoflavones found in soy are genistein, daidzein, and glycitein [16]. Divi et al. have shown with in vitro andin vivo studies [17-18] that isoflavones inhibit the activity of thyroid peroxidase (TPO). Soy has been shown to cause thyroid dysfunctions in susceptible individuals and prevent the absorption of synthetic thyroid hormones [19-20]. Genisteins are known to affect cardiomyocytes, breast cancer cells, and osteoblasts in a dose-dependent manner [21-22]. Tran et al. demonstrated that; while 1-10 $\mu \mathrm{M}$ genistein induced thyrocyte hyperfunctioning, $100 \mu \mathrm{M}$ genistein reversed those changes [22]. In vitro studies have shown that genistein and daidzein block TPO-catalyzed tyrosine iodination by acting as alternate substrates for iodination [18]. The incubation of either genistein or daidzein with TPO in the presence of hydrogen peroxide inactivates TPO irreversibly but the addition of iodide to the medium abolishes this inactivation [23]. These in vitro data show that soy increases the requirement for iodine [24].

Several hypotheses have been suggested about the effects of soy on the thyroid gland. Soy is rich in phytate; which can bind T3 and increase its elimination via faeces [25]. Isoflavones can bind to thyroid hormone receptors, resulting from their structural similarity with T3 [26] ; reduce plasma protein binding to T4, or reduce the rate of $\mathrm{T} 4$ deiodination, which is a reaction to produce $\mathrm{T} 3$ with the 5'-deiodinase type I acting as the catalyzing enzyme $[27]$.

Of three studies, investigating the changes in serum TSH levels in adult women, only one demonstrated statistically significant TSH level alterations. Persky et al. found out increased TSH levels in the third and sixth months compared to the control group fed with fat-free milk. Studies investigating only the serum levels of free T3 and free T4 reported increases in the range of 8 to 16\% [28-31]. However, those values were not statistically significant. Dillingham et al. have carried out the most comprehensive study so far, in which they investigated the effects of soy on thyroid function in male individuals. In that study, 35 young adult men were fed with a diet containing approximately $32 \mathrm{~g}$ of isoflavones. The study did not find any statistically significant differences in the serum levels of total T3, free T3, total T4, free T4, TSH, and thyroxine-binding globulin [26]. As it is observed, the studies on adults report variable results.

Also, experimental and clinical studies on fetuses and newborns obtained variable results similar to the results obtained in adult studies. Chang et al. demonstrated that in utero feeding of the rats with a diet containing $500 \mathrm{ppm}$ starting from the 20th weeks of gestation resulted in the inactivation of thyroid peroxidase by approximately $50 \%$. However, they observed no changes in the serum levels of T3, T4, and TSH; in the weight of the thyroid gland, or in the histopathological examination findings [32-3] . Conversely, Son et al. demonstrated that soy-containing diet caused thyroid hyperplasia in female rats, especially when the iodide intake was inadequate [34]. Conrad et al. [10] showed a prolonged increase in the serum TSH levels in infants fed with soy-containing formulas in comparison to those fed with soy-free formula. In their retrospective study on infants with hypothyroidism; Conrad et al. reviewed 70 infants fed with non-soy formulas and 8 infants fed with soy-containing formulas. After 4 months of L-thyroxine treatment, they observed similar T4 levels in the two groups but the levels of TSH increased in $17 \%$ of the infants fed with soy-free formula and in $62.5 \%$ of the infants fed with soy formula.

In our study, we observed body weight increases in the subjects of both soy and non-soy formula fed groups compared to the subjects fed with standard pellet feed in the control group. However, these changes were 
not statistically significant. We think that these findings occurred because of the higher calorie counts of the infant formulas than those of the rat pellet feed.

We observed that serum free T3, free T4, and TSH levels increased in a dose-dependent manner in soyfed subjects and that those increases were statistically significant in subjects consuming high-dose (2.64g / $100 \mathrm{ml}$ ) soy-containing foods. Furthermore; we found that the inflammation parameters of the thyroid gland, Anti TG and Anti TPO, did not increase in subjects receiving low-dose soy but these parameters increased significantly in subjects receiving high-dose soy. In the histopathological examination, we observed a mild increase in the subjects fed with the high-dose soy formula but this change was not statistically significant. When we make an overall assessment of our study findings; we observe that feeding high-dose soy formula induces inflammation in the thyroid tissue, resulting in increased thyroid hormone release independently from suppressing effects of TSH. The reason why this functional change is not reflected in the histopathological findings in our study might be related to the duration of the feeding with the formulas. A longer duration of high-dose soy intake may induce more significant inflammation in the thyroid tissue.

In conclusion; feeding infants with high-dose soy containing formulas may trigger inflammatory processes in the thyroid tissue, resulting in thyroid dysfunction. As it is known that thyroid hormones are involved as catalyzers in many chemical reactions in the body, infant formulas with high soy content may cause several metabolic problems in babies in the long term.

\section{References}

1. Weggemans RM, Trautwein EA. Relation between soy- associated isoflavones and LDL and HDL cholesterol concentrations in humans: A meta-analysis. Eur J Clin Nutr 2003; 57:940-946.

2. Nestel P. Isoflavones: their effects on cardiovascular risk and functions. Curr Opin Lipidol 2003;14:3-8.

3. Yamamoto S, Sobue T, Kobayashi M, Sasaki S, Tsugane S. Soy, isoflavones, and breast cancer risk in Japan. J Natl Cancer Inst 2003;95:906-913.

4. Lamartiniere CA, Cotroneo MS, Fritz WA, Wang J, Men- tor-Marcel R, Elgavish A. Genistein chemoprevention: timing and mechanisms of action in murine mammary and prostate. J Nutr 2002;132:552558.

5. Messina M, Ho S, Alekel DL. Skeletal benefits of soy isoflavones: A review of the clinical trial and epidemiologic data. Curr Opin Clin Nutr Metab Care 2004;7:649-658.

6. Miniello VL, Moro GE, Tarantino M, Natile M, Granieri L, Armenio L. Soy-based formulas and phytooestrogens: a safety profile. Acta Paediatr Suppl 2003;91:93-100.

7. Messina M, Redmond G. Effects of soy protein and soybean isoflavones on thyroid function in healthy adults and hypothyroid patients: a review of the relevant literature. Thyroid 2006;16:249-58.

8. Schmutzler C, Gotthardt I, Hofmann PJ, Radovic B, Kovacs G, Stemmler L, Nobis I, Bacinski A, Mentrup B, Ambrugger P, Gru ters A, Malendowicz LK, Christoffel J, Jarry H, Seidlova'-Wuttke D, Wuttke W, Ko hrle J. Endocrine disruptors and the thyroid gland - a combined in vitro and in vivo analysis of potential new biomarkers. Environ Health Perspect 2007;115:77-83.

9. Gaertner FC, Rohde F, Mueller J, Blechert B, Janssen KP, Essler M. Endogenous expression of the sodium iodide symporter mediates æuptake of iodide in murine models of colorectal carcinoma. Int J Cancer 2009;125:2783-91.

10. Kohrle J. Thyroid hormone deiodination in target tissues - a regulatory role for the trace element selenium? Exp Clin Endocrinol 1994;102:63-89.

11. LevyO, DaiG, RiedelC, GinterCS, PaulEM, LebowitzAN,CarrascoN. Characterization of the thyroid $\mathrm{Na}+$ /I- symporter with an anti-COOH terminus antibody. Proc Natl Acad Sci USA 1997;94:5568-5573.

12. Van Wyk JJ, Arnold MB, Wynn J, Pepper F. The effects of a soybean product on thyroid function in humans. Pediatrics 1959;24:752-760.

13. Hydovitz JD 1960 Occurrence of goiter in an infant on a soy diet. N Engl J Med 1960;262:351-353

14. Diel P, Geis RB, Caldarelli A, Schmidt S, Leschowsky UL, Voss A, Vollmer G. The differential ability of the phy- toestrogen genistein and of estradiol to induce uterine weight and proliferation in the rat is associated with a sub- stance specific modulation of uterine gene expression. Mol Cell Endocrinol 
2004:221:21-32.

15. Wuttke W, Jarry H, Becker T, Schultens A, Christoffel V, Gorkow C, Seidlova-Wuttke D. Phytoestrogens: En- docrine disrupters or replacement for hormone replacement therapy? Maturitas 2003;44:9-20.

16. Murphy PA, Song T, Buseman G, Barua K, Beecher GR, Trainer D, Holden J. Isoflavones in retail and institu- tional soy foods. J Agric Food Chem 1999;47:2697-2704.

17. Divi RL, Doerge DR. Inhibition of thyroid peroxidase by dietary flavonoids. Chem Res Toxicol 1996;9:16-23.

18. Divi RL, Chang HC, Doerge DR. Anti-thyroid isoflavones from soybean: isolation, characterization, and mechanisms of action. Biochem Pharmacol 1997;54:1087-1096.

19. Doerge DR, Sheehan DM. Goitrogenic and estrogenic activity of soy isoflavones. Environ Health Perspect 2002;110:349-353.

20. Conrad SC, Chiu H, Silverman BL. Soy formula complicates management of congenital hypothyroidism. Arch Dis Child 2004;89:37-40.

21. Sun Z, Biela LM, Hamilton KL, Reardon KF. Concentration-dependent effects of the soy phytoestrogen genistein on the proteome of cultured cardiomyocytes. J Proteomics 2012;75:3592-604.

22. Cappelletti V, Fioravanti L, Miodini P, Di Fronzo G. Genistein blocks breast cancer cells in the G(2)M phase of the cell cycle. J Cell Biochem 2000;79:594-600.

23. Doerge D, Chang H. Inactivation of thyroid peroxi- dase by soy isoflavones, in vitro and in vivo. J Chromatogr B Analyt Technol Biomed Life Sci 2002;777:269-271.

24. Ikeda T, Nishikawa A, Son HY, Nakamura H, Miyauchi M, Imazawa T, Kimura S, Hirose M. Synergistic effects of high-dose soybean intake with iodine deficiency, but not sulfadimethoxine or phenobarbital, on rat thyroid prolifer- ation. Jpn J Cancer Res 2001;92:390-395.

25. Bhatia J, Greer F Committee on Nutrition. Use of soy protein-based formulas in infant feeding. Pediatrics 2008;121:1062-1068.

26. Dillingham BL, McVeigh BL, Lampe JW, Duncan AM. Soy protein isolates of varied isoflavone content do not influence serum thyroid hormones in healthy young men. Thyroid 2007;17:131-137.

27. de Souza dos Santos MC, Gontalves CFL, Vaisman M, Ferreira ACF, de Carvalho DP. Impact of flavonoids on thyroid function. Food Chem Toxicol 2011;49:2495-502.

28. Duncan AM, Underhill KE, Xu X, Lavalleur J, Phipps WR, Kurzer MS 1999 Modest hormonal effects of soy isoflavones in postmenopausal women. J Clin Endocrinol Metab 1999;84:3479-3484.

29. Bruce B, Messina M, Spiller GA. Isoflavone supplements do not affect thyroid function in iodine-replete post- menopausal women. J Med Food 2003;6:309-316.

30. Roughead ZK, Hunt JR, Johnson LK, Badger TM, Lykken GI. Controlled substitution of soy protein for meat protein: Effects on calcium retention, bone, and cardiovascular health indices in postmenopausal women. J Clin En docrinol Metab 2005;90:181-189.

31. Persky VW, Turyk ME, Wang L, Freels S, Chatterton R, Jr., Barnes S, Erdman J, Jr, Sepkovic DW, Bradlow HL, Potter S. Effect of soy protein on endogenous hor- mones in postmenopausal women. Am J Clin Nutr 2002;75:145-153.

32. Chang HC, Doerge DR. Dietary genistein inactivates rat thyroid peroxidase in vivo without an apparent hypothyroid effect. Toxicol Appl Pharmacol 2000;168:244-252.

33. Chang HC, Churchwell MI, Delclos KB, Newbold RR, Do- erge DR. Mass spectrometric determination of Genis- tein tissue distribution in diet-exposed Sprague-Dawley rats. J Nutr 2000;130:1963-1970.

34. Son HY, Nishikawa A, Ikeda T, Imazawa T, Kimura S, Hi- rose M. Lack of effect of soy isoflavone on thyroid hyperplasia in rats receiving an iodine-deficient diet. Jpn J Cancer Res 2001;92:103-108.

\begin{tabular}{ll}
\hline Grades & Definition \\
\hline 0 & No fibrosis (no fibroblasts and/or collagen fibres) \\
1 & Slight fibrosis (few fibroblasts and/or collagen fibres) \\
2 & Median fibrosis (more fibroblasts and/or collagen fibres) \\
3 & Severe fibrosis (lots of fibroblasts and/or collagen fibres) \\
\hline
\end{tabular}


Table-1: The histopathological fibrosis scoring system

\begin{tabular}{|c|c|c|c|c|}
\hline & GROUP $1($ Mean士Sd $)$ & GROUP $2($ Mean士Sd $)$ & GROUP 3 (Mean \pm Sd) & GROUP 4 (Me \\
\hline TSH (day 0) & $11.20 \pm 4.22$ & $7.69 \pm 0.92$ & $7.93 \pm 1.25$ & $8.78 \pm 1.33$ \\
\hline TSH (day 90) & $13.61 \pm 1.38$ & $13.59 \pm 3.04$ & $13.70 \pm 4.00$ & $21.55 \pm 3.80$ \\
\hline Free T3 (day 0) & $3.41 \pm 1.61$ & $1.75 \pm 0.39$ & $1.85 \pm 0.54$ & $2.22 \pm 0.57$ \\
\hline Free T3 (day 90) & $4.30 \pm 0.60$ & $5.12 \pm 1.15$ & $4.34 \pm 1.72$ & $7.72 \pm 1.64$ \\
\hline Free T4 (day 0) & $1.25 \pm 0.87$ & $0.51 \pm 0.23$ & $0.36 \pm 0.26$ & $0.46 \pm 0.34$ \\
\hline Free T4 (day 90) & $1.69 \pm 0.35$ & $2.18 \pm 0.68$ & $1.89 \pm 0.71$ & $3.73 \pm 0.97$ \\
\hline
\end{tabular}

\begin{tabular}{llllll}
\hline Anti TPO (day 0) & $4.00 \pm 1.13$ & $2.58 \pm 0.31$ & $4.03 \pm 0.42$ & $2.94 \pm 0.45$ & 0.141 \\
\hline Anti TPO (day 90) & $4.56 \pm 0.46$ & $5.19 \pm 0.89$ & $4.59 \pm 1.34$ & $3.79 \pm 1.27$ & $<0.001$ \\
Anti TG (day 0) & $2.20 \pm 1.01$ & $1.08 \pm 0.47$ & $2.24 \pm 0.37$ & $1.26 \pm 0.40$ & 0.141 \\
Anti TG (day 90) & $2.70 \pm 0.41$ & $3.27 \pm 0.80$ & $2.73 \pm 1.20$ & $2.02 \pm 1.14$ & 0.002 \\
\hline
\end{tabular}

Table 2. Serum levels of the study variables at baseline (day 0) and at the end of the study (day 90) with p-values (One-way ANOVA test).

\begin{tabular}{lllll}
\hline & GROUP 1 & GROUP 2 & GROUP 3 & GROUP 4 \\
\hline Subject 1 & 0 & 1 & 0 & 1 \\
Subject 2 & 0 & 0 & 0 & 1 \\
Subject 3 & 0 & 0 & 0 & 0 \\
Subject 4 & 0 & 0 & 1 & 0 \\
Subject 5 & 0 & 1 & 0 & 0 \\
Subject 6 & 0 & 0 & 0 & 1 \\
Subject 7 & 0 & 0 & 0 & 0 \\
\hline
\end{tabular}

Table 3. Histopathological fibrosis scores of the subjects by the groups .

\begin{tabular}{lll}
\hline & Day 0 & Day 90 \\
\hline GROUP 1 & 50.4 & 280.6 \\
GROUP 2 & 57.2 & 335.4 \\
GROUP 3 & 61.4 & 362.7 \\
GROUP 4 & 52.5 & 346.5 \\
\hline
\end{tabular}

Table 4. The mean body weight of the subjects by the groups on days 0 and 90 .

List of abbreviations

Antithyroglobulin antibody : Anti TG

Anti-troponin antibody: Anti TPO

Thyroid stimulating hormone: TSH

Thyroid peroxidase: TPO 